\title{
Effect of follicular wave synchronization on superovulatory response of Girolando embryo donors
}

\author{
Joaquim Esquerdo Ferreira', Marco Roberto Bourg de Mello ${ }^{1}$, Pedro Afonso de Preaulx \\ Moreira Alves², Raquel Rodrigues Costa Mello', Helcimar Barbosa Palhano ${ }^{3}$
}

\footnotetext{
${ }^{1}$ Departamento de Reprodução e Avaliação Animal, Instituto de Zootecnia, Universidade Federal Rural do Rio de Janeiro, Seropédica, RJ, Brasil.

${ }^{2}$ Empresa de Pesquisa Agropecuária do Estado do Rio de Janeiro, Centro de Pesquisa em Agricultura Orgânica, Seropédica, RJ, Brasil.

${ }^{3}$ Departamento de Biologia Animal, Instituto de Biologia, Universidade Federal Rural do Rio de Janeiro, Seropédica, RJ, Brasil.
}

\begin{abstract}
The objective of this study was to evaluate the effect of the follicular wave synchronization method on the superovulatory response of Girolando embryo donors. Seven cows and five heifers were divided into three treatments according to the method of the follicular wave synchronization prior to superovulation. The donors were superovulated with eight FSH decreasing doses, adding $133 \mathrm{mg}$ per animal. The superovulatory response was evaluated using an ultrasound device to quantify the number of corpora lutea. The number and quality of recovered structures were also evaluated. Animal category (cow or heifer) and genetic group influenced the superovulatory response, in which heifers showed a greater response $(100 \%$ in all treatments) compared with cows, which showed $85.7 \%, 57.1 \%$ and $57.1 \%$ superovulatory response for standing estrus, GnRH and P4 + BE groups, respectively. The genetic group also showed influence on superovulatory response, in which the $3 / 8$ animals had an average of 10.3 corpora lutea per donor compared with the $3 / 4$ animals, which showed 4.9 . The follicular wave synchronization treatments did not show differences in superovulatory response, recovered structures and viable structures. The treatment of follicular wave synchronization with GnRH or with P4 + BE can be used in Girolando donors with the same efficiency as the standing estrus group, and 3/8 Girolando heifers respond better to the superovulatory treatment.
\end{abstract}

Key Words: animal category, Bos taurus indicus, embryo transfer, genetic group

\section{Introduction}

The embryo Transfer (ET) biotechnology allows us to collect embryos from a female donor and transfer them to recipient females, which will carry the pregnancy to term. It is relevant for animal production, because it causes females to produce a higher number of offspring than would be possible to obtain physiologically during their reproductive life. Thus, it is an important biotechnological tool for improving livestock and can be used to accelerate and enhance precision in animal selection processes (Baruselli et al., 2000).

According to the Brazilian Embryo Transfer Society, despite the increase in in vitro embryo production in Brazil, in vivo embryo production showed a significant decrease in 2009 (Stroud and Bó, 2011), due to a reduction in superovulations. The standard protocol that relies on superovulation after estrus detection still has some limitations, such as the need for heat detection, the need to start the superovulatory treatment at a specific time of the estrous cycle, the inability to schedule several

Received August 26, 2013 and accepted August 28, 2014

Corresponding author: esquerdovet@gmail.com

http://dx.doi.org/10.1590/S1516-35982014001100002

Copyright $(2014$ Sociedade Brasileira de Zootecnia. This is an Open Access article distributed under the terms of the Creative Commons Attribution Non-Commercial License, which permits unrestricted non-commercial use, distribution, and reproduction in any medium, provided the original work is properly cited. collections on the same day, the inconsistency of results, and the fact that 20 to $30 \%$ of donors do not respond to the superovulatory treatment (Baruselli et al., 2006). This variability in superovulatory response remains one of the toughest challenges in ET programs in cattle (Mapletoft et al., 2002; Barros, 2004; Baruselli et al., 2006).

Alternatives to control the follicular wave emergence at any time during the estrous cycle, without the need for estrus detection, can facilitate the management of Bos taurus taurus and Bos taurus indicus donors, and increase the efficacy of ET programs (Baruselli et al., 2006, Bó et al., 2006).

The objective of this study was to evaluate the effect of follicular wave synchronization on superovulatory response of bovine embryo donors, and assess the effect of crossbreed level and different categories (cows and heifers) on superovulatory response of Girolando embryo donors.

\section{Material and Methods}

This experiment was carried out at the Agricultural Research Corporation of the State of Rio de Janeiro (PESAGRO-RIO), in the Dairy Cattle Department of the Center for Research in Organic Agriculture, located in Seropedica, Rio de Janeiro, from November 2010 to December 2011.

Twelve non-lactating, non-pregnant Girolando embryo donors (seven cows and five heifers) with genetic group 
ranging from $3 / 8$ to $3 / 4$, presenting body condition score between 3.0 and 4.0 on a scale from 1.0 to 5.0 (Wildman et al., 1982), registered in ABCZ (Brazilian Association of Zebu Breeders) and aged between 3 and 10 years were used.

These donors were divided into three treatments for synchronization of follicular wave emergence before superovulation. This way the three treatments were applied in all donors, but at different times.

The animals were divided into three groups (I, II and III), so that each group was composed of cows and heifers and presented the same number of animals from different genotypes $(3 / 8,1 / 2$ and $3 / 4)$.

The three groups for synchronization of follicular wave emergence were as follows, Group 1: observation of "standing estrus" of donor and beginning of superovulation on the tenth day after estrus (control group; Figure 1);

Group 2: at unknown stage of the estrous cycle (day 0), the donors received an intravaginal device containing $1 \mathrm{~g}$ of progesterone $\left(\mathrm{DIB}^{\circledR}\right.$ ) and $2 \mathrm{mg}$ of estradiol benzoate $\left(\right.$ Sincrodiol $\left.{ }^{\circledR}\right)$. At D4, the superovulation was started (Figure 2);

Group 3: the superovulation was initiated four days after the application of $25 \mathrm{mcg}$ of GnRH (Gestran Plus ${ }^{\circledR}$ ) in all donors (Figure 3).

All donors underwent gynecological examination by ultrasonography to detect cyclicity and reproductive-tract abnormalities 30 days before the start of the superovulatory treatment. All donors were kept on a Brachiaria decumbens grass pasture, and had ad libitum access to water and mineral salt. Animals underwent ectoparasite and endoparasite control, as well as sanitary control, according to the routine method used in the herd. In addition to the nutritional status, the selection criteria of the twelve donors also included reproductive history, age, health condition and genetic group (crossbreed level).

Donor animals of all experimental groups were subjected to the same superovulatory protocol with folliclestimulating hormone - FSH (Folltropin $\left.{ }^{\circledR}\right)$. To this end, $133 \mathrm{mg}$ of FSH were used in each donor and divided into eight decreasing doses, applied twice daily in 12-h intervals between each application. At the beginning of the third day of the superovulation protocol, $0.5 \mathrm{mg}$ of cloprostenol $\left(\right.$ Sincrocio $\left.^{\circledR}\right)$, a PGF2 $\alpha$ (IM) analog, was used. Twelve hours after the last FSH injection, $25 \mu \mathrm{g}$ of GnRH (Gestran Plus ${ }^{\circledR}$ ) was administered to induce ovulation. In Group II, the intravaginal implant was removed at the end of the superovulatory protocol. During the experiment, artificial inseminations (AI) were performed 12 and 24 hours after GnRH application, with the use of conventional semen (single match) from a Girolando bull.
Superovulatory response was assessed seven days after the first artificial insemination by the same technician, who performed ultrasound examinations by transrectal technique with a $7.5 \mathrm{MHz}$ linear-array transducer (MINDRAY ${ }^{\circledR}$ D2200 VET) in all animals. The donor ovaries were examined to determine the number of corpora lutea and observe possible anovulatory follicles. Uterine flushing for embryo recovery was performed only in donors that responded to the superovulatory protocol (showing more than two corpora lutea on the collection day).

Uterine flushing (nonsurgical) for embryo collection was performed seven days after the first insemination, and was performed by the same technician. After uterine flushing, the media with embryos was immediately taken

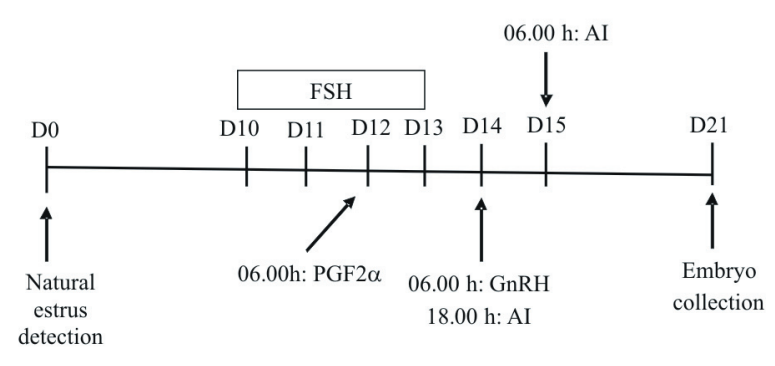

FSH - follicle-stimulating hormone; D - day; AI - artificial insemination.

Figure 1 - Donor superovulation protocol in control group (Group I).

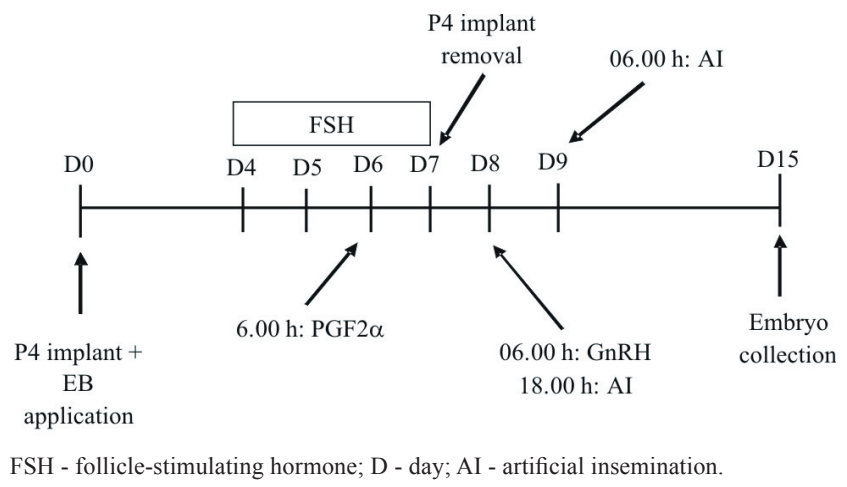

Figure 2 - Donor superovulation protocol in Group II.

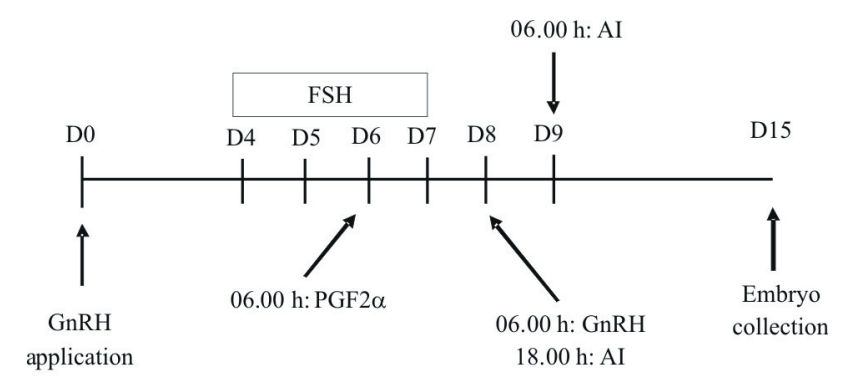

FSH - follicle-stimulating hormone; D - day; AI - artificial insemination.

Figure 3 - Donor superovulation protocol in Group III. 
to the laboratory for the necessary procedures for embryo localization and manipulation. The media containing embryos was carefully poured onto a plastic petri dish, which was taken to the stereomicroscope $\left(\right.$ Neovet $\left.^{\circledR}\right)$ to identify the embryos under an increase of 40X. As the embryos were located, they were transferred to another plastic petri dish containing Phosphate Buffered Saline (PBS) plus 0.4\% BSA (TQC Holding ${ }^{\circledR}$ ). The embryos were subjected to flushes in the same way, and then morphologically classified under a stereomicroscope (40X).

Morphological classification is subjective and is performed according to developmental stage (unfertilized, 2-8 cell, 8-16 cell, morula - M, early morula - MI, compact morula - MC, early blastocyst - BI, blastocyst - BL, and expanded blastocyst - BX) and quality (grade I - Excellent, grade II - Good, grade III - Regular, and grade IV - Poor). To avoid discrepancies in classification the same technician classified all embryos in accordance with the manual of International Embryo Transfer Society - IETS (Stringfellow \& Seidel, 1998).

The number of recovered embryos, and the quality of these structures were taken into account, when comparing different treatments for ovulation synchronization of donors. Twelve donors were grouped into three treatments by age group (nulliparous and multiparous) and genetic group (crossbreed level), and each donor was subjected to three treatments at 40-day intervals between superovulations (by Latin Square design).

Data were analyzed using the statistical program ASSISTAT (version 7.6 beta). The Tukey test was used to test the influence of genetic group on the superovulatory response; the number of corpora lutea; recovered structures and viable embryos. The percentage of animals that did not respond to treatment was assessed by the Shapiro-Wilk test. A significance level of 5\% was considered in all analyses.

\section{Results and Discussion}

For heifers and cows, after a total of 12 superovulations for each treatment, the superovulatory responses were $100 \%$ vs. $85.7 \%, 100 \%$ vs. $57.1 \%$, and $100 \%$ vs. $57.1 \%$ for natural estrus, GnRH, and P4 + EB groups, respectively (Table 1).
There was a statistical difference $(\mathrm{P}<0.05)$ between heifers and cows when comparing the superovulatory response within each group, and heifers showed a higher response than cows in all three treatments. No statistical difference was found $(\mathrm{P}>0.05)$ between the superovulatory response of heifers and cows of the different groups.

The results in Table 1 differ from those reported by Hasler et al. (1981), where Holstein heifers and cows showed no statistical difference in superovulatory response. The difference between the present results and those reported by Hasler et al. (1981) can be explained by the lower number of donors used in this study, different breeds or differences in superovulation protocols used in both experiments. In a study conducted by Lima (2007), no difference was found between heifers and cows in relation to superovulatory response, which differs from the present study. These findings can be explained by the different breeds used by Lima (2007), who used Limousin breed animals, and also by the higher number of superovulations performed (244 versus 36). These results differ from the present study in relation to superovulatory response, which was better in heifers as compared with cows. This difference could be explained by the superovulation protocol used in said experiment, with the same dose of FSH $(133 \mathrm{mg})$ per donor, for all animal categories.

A study conducted by Lerner et al. (1986) with 339 Holstein donors reported that the increased donor age reduces the number of recovered structures and viable embryos. An alternative proposed by these authors to change this situation would be to increase the FSH dose, but this increase did not have the same result in heifers. In heifers, the increase in FSH dose caused a decrease in the number of recovered structures because there is a physical limitation of the ovary, which reduces the blood supply to individual follicles. This reduction may interfere with the appropriate follicular development and ovulation. Thus, a greater number of follicles would be stimulated to continue development with high doses of FSH, but few would be able to ovulate and undergo luteinization or could become atretic in younger animals.

The average number of corpora lutea for natural estrus, GnRH, and P4 + EB groups were 6.7, 5.0 and 8.2 per donor,

Table 1 - Superovulatory response of Girolando heifers and cows according to the follicular wave synchronization treatment

\begin{tabular}{|c|c|c|c|c|}
\hline \multirow{2}{*}{ Treatments } & \multicolumn{2}{|c|}{ Heifers } & \multicolumn{2}{|c|}{ Cows } \\
\hline & SOV (n) & Superovulatory response & SOV (n) & Superovulatory response \\
\hline Natural estrus & 5 & $100 \%$ a & 7 & $85.7 \% \mathrm{~b}$ \\
\hline GnRH & 5 & $100 \%$ a & 7 & $57.1 \% \mathrm{~b}$ \\
\hline $\mathrm{P} 4+\mathrm{EB}$ & 5 & $100 \%$ a & 7 & $57.1 \% \mathrm{~b}$ \\
\hline
\end{tabular}

P4 - progesterone implant; EB - estradiol benzoate; SOV - superovulation.

Means followed by different letters within the same row differ by the Shapiro-Wilk test at $5 \%$. 
respectively (Table 2). In regard to the total structures and viable embryos per donor, the averages were 3.2, 1.9 and 5.5 by total structures, and $2.8,1.8$ and 4.3 by viable embryos, respectively, for natural estrus, $\mathrm{GnRH}$, and $\mathrm{P} 4$ + EB groups. There was no statistical difference $(\mathrm{P}>0.05)$ between treatments for any of the evaluated parameters.

The ability to synchronize follicular wave emergence, in order to know the phase of the estrous cycle to superovulation, has important implications for embryo transfer programs (Bó et al., 1996). According to Moor et al. (1984), differences in follicular growth dynamics and particularities of each donor, such as the size, distribution and condition of antral follicles at the time of administration of FSH, may affect the superovulatory response.

The results presented in Table 2 are consistent with the findings of Nasser et al. (2011), who did not observe differences in the number of recovered structures and viable embryos when comparing the natural estrus and synchronization estrus with progesterone and estradiol benzoate (EB) in superovulated cows.

However, results of this study differ from those found by Fischdick et al. (2009), who reported significant differences between the follicular wave emergence synchronization methods on superovulatory response of Simmental, Limousin and Red Angus cows. In these studies, a synchronized group has a greater number of structures recovered and viable embryos. This difference may be explained by the different methods used by these authors for synchronization of follicular wave emergence, which evaluated the efficacy of a follicular ablation method associated with progesterone.

The average number of corpora lutea per donor was 10.3, 6.1, and 4.9 for crossbreed levels $3 / 8,1 / 2$, and $3 / 4$, respectively (Table 3 ). The average recovered structures and viable embryos per donor were 6.5, 3.7, and 1.9, and 5.1, 3.2 and 1.7 , respectively, for crossbreed levels $3 / 8,1 / 2$ and $3 / 4$. There was statistical difference $(\mathrm{P}<0.05)$ between genetic groups in the number of corpora lutea, and $3 / 8$ Holstein donor (5/8 Gir) showed higher response to superovulatory treatment when compared with the $3 / 4$ Holstein donor

Table 2 - Average corpora lutea, total structures and viable embryos per Girolando donor according to the follicular wave synchronization treatment

\begin{tabular}{lccc}
\hline \multirow{2}{*}{ Treatments } & \multicolumn{3}{c}{ Evaluated parameters } \\
\cline { 2 - 4 } & Corpora lutea & Total structures & Viable embryos \\
\hline Natural estrus & $6.7 \mathrm{a}$ & $3.2 \mathrm{a}$ & $2.8 \mathrm{a}$ \\
GnRH & $5.0 \mathrm{a}$ & $1.9 \mathrm{a}$ & $1.8 \mathrm{a}$ \\
P4 + EB & $8.2 \mathrm{a}$ & $5.5 \mathrm{a}$ & $4.3 \mathrm{a}$ \\
\hline
\end{tabular}

P4 - progesterone implant; EB - estradiol benzoate.

Means followed by the same letter within the same column do not differ by Tukey's test at $5 \%$.
( $1 / 4$ Gir). There was no statistical difference $(\mathrm{P}>0.05)$ for $1 / 2$ Holstein donor (1/2 Gir) in relation to other genetic groups. There was no statistical difference $(\mathrm{P}>0.05)$ in relation to the recovered structures and viable embryos for the three genetic groups.

Several differences in reproductive physiology have been reported between Bos taurus taurus and Bos taurus indicus breeds, which can in part explain the variations in superovulatory response between breeds belonging to these genetic groups. Some of these differences include the diameter of the dominant follicle, the duration of estrus expression and greater sensitivity to the exogenous gonadotropins in zebu cattle (Baruselli et al., 2006).

These reports may support the results presented in Table 3, in which animals with higher proportion of zebu responded better to the superovulatory protocol when compared with animals with a greater taurine genotype. This difference in superovulatory response may be explained by the fact that a single dose of FSH (133 mg) was used to superovulate all animals, and Bos taurus indicus animals are more sensitive to exogenous gonadotropins and respond better to superovulation.

Thus, it would be more interesting if superovulatory protocols were developed specifically for each breed, optimizing the reproductive potential of each genetic group in embryo transfer programs. However, this difference between the genetic groups is not the only limiting factor because there is also the individual factor, which can be decisive in taurine and zebu cattle. Baruselli et al. (2003) reported this individual variation in Nellore cattle. These authors found that the donor was the largest source of variation in the embryo transfer program, showing the individual effect in the recovery rate, recovered structures, transferable embryos and number of corpora lutea.

However, it is necessary to know the reproductive physiology of these breeds in order to improve the protocols used for each genetic group, optimizing the superovulatory response and reducing the excessive cost associated with hormone treatments. Within the same breed, potential reproductive variations could be found in the present study in relation to different superovulatory responses when $3 / 8$ Girolando were compared with $3 / 4$ Girolando donors. The

Table 3 - Average corpora lutea, total structures and viable embryos per donor according to the genetic group

\begin{tabular}{lccc}
\hline Genetic group & Corpora lutea & Total structures & Viable embryos \\
\hline $3 / 8$ & $10.3 \mathrm{a}$ & $6.5 \mathrm{a}$ & $5.1 \mathrm{a}$ \\
$1 / 2$ & $6.1 \mathrm{ab}$ & $3.7 \mathrm{a}$ & $3.2 \mathrm{a}$ \\
$3 / 4$ & $4.9 \mathrm{~b}$ & $1.9 \mathrm{a}$ & $1.7 \mathrm{a}$ \\
\hline
\end{tabular}

Means followed by different letters within the same column differ by Tukey's test at $5 \%$. 
correct interpretation of the various factors that influence the superovulatory response is extremely important to enhance the use of reproduction biotech in this breed.

\section{Conclusions}

The follicular wave emergence synchronization with GnRH or the combination of P4 + BE are as efficient as the use of standing estrus for superovulation of Girolando embryo donors. Girolando donors with a $3 / 8$ crossbreed level respond better to superovulatory treatment when compared with 3/4 Girolando, and Girolando heifers respond better to superovulatory treatment as compared with cows.

\section{Acknowledgments}

The authors thank the Agricultural Research Corporation of the State of Rio de Janeiro (PESAGRO-RIO), for granting the Girolando breed animals and infrastructure support for this study; CAPES, for the financial support provided by the granting of the Master stock to the first author; and the Department of Animal Breeding and Evaluation of Universidade Federal Rural do Rio de Janeiro, for the support of this research.

\section{References}

Barros, C. M. and Nogueira, M. F. G. 2004. Superovulação em zebuínos de corte. p.212-222. In: Anais do 1 Simpósio Internacional de Reprodução Animal Aplicada, Londrina-PR.

Baruselli, P. S.; Marques, M. O.; Carvalho, N. A. T.; Madureira, E. H. and Costa Neto, W. P. 2000. Dinâmica folicular em novilhas receptoras de embrião bovino submetidas à sincronização da ovulação para inovulação em tempo fixo. Arquivos da Faculdade de Veterinária da UFRGS 28:217.

Baruselli, P. S.; Marques, M. O.; Reis, E. L.; Nasser, L. F. T.; Silva, R. C. P.; Menegatti, J. A.; Valentin, R. and Santos, I. C. C. 2003. Adequação da dose de FSH (Folltropin-v) em protocolos de superovulação de vacas Nelore (Bos indicus) com inseminação artificial em tempo fixo (SOTF). Acta Scientiae Veterinariae 31:244-245.

Baruselli, P. S.; Sá Filho, M. F.; Martins, C. M.; Nasser, L. F. T.; Nogueira, M. F. G.; Barros, C. M. and Bó, G. A. 2006.
Superovulation and embryo transfer in Bos indicus cattle. Theriogenology 65:77-88.

Bó, G. A.; Adams, G. P.; Pierson, R. A. and Mapletoft, R. J. 1996. Effect of progestogen plus estradiol-17beta treatment on superovulatory response in beef cattle. Theriogenology 45:897-910.

Bó, G. A.; Baruselli, P. S.; Chesta, P. M. and Martins, C. M. 2006. The timing of ovulation and insemination schedules in superstimulated cattle. Theriogenology 65:89-101.

Fischdick, R. O.; Rodrigues, C. F. M.; Pinho, T. G.; Brandão, F. Z.; Cavalcanti, A. S.; Boité, M. C. and Nogueira, L. A. 2009. Comparação de diferentes técnicas de sincronização da emergência da onda folicular visando a superovulação em bovinos. Revista Brasileira de Ciência Veterinária 16:119-123.

Hasler, J. F.; Brooke, G. P. and McCauley, A. D. 1981. The relationship between age and response to superovulation in Holstein cows and heifers. Theriogenology 15:109 (abstr.).

Lerner, S. P.; Thayne, W. V. and Baker, R. D. 1986. Age, dose of FSH and other factors affecting superovulation in Holstein cows. Journal of Animal Science 63:176-183.

Lima, W. M. 2007. Resposta superovulatória após ablação folicular usando um dispositivo simplificado em bovinos (Bos taurus taurus). Dissertação (M.Sc.). Universidade Federal do Rio Grande do Sul, Porto Alegre.

Mapletoft, R. J.; Steward, K. B. and Adams, G. P. 2002. Recent advances in the superovulation in cattle. Reproduction, Nutrition and Development 42:601-611.

Moor, R. M.; Kruip, T. A. and Green, D. 1984. Intraovarian control of folliculogenesis: limit to superovulation? Theriogenology 21:103-116

Nasser, L. F.; Sá Filho, M. F.; Reis, E. L.; Rezende, C. R.; Mapletoft, R. J.; Bó, G. A. and Baruselli, P. S. 2011. Exogenous progesterone enhances ova and embryo quality following superstimulation of the first follicular wave in Nellore (Bos indicus) donors. Theriogenology 76:320-327.

Stringfellow, D. A. and Seidel, S. M. 1998. Manual of the International Embryo Transfer Society: a procedural guide and general information for the use of embryo transfer technology emphasizing sanitary procedures. 3rd ed. International Embryo Transfer Society, Savoy, IL.

Stroud, B. and Bó, G. A. 2011. Estatísticas mundiais de 2009 para transferência embrionária em animais domésticos de fazenda; Resumo do relatório da Comissão de Recuperação de Dados da Sociedade Internacional para Transferência de Embriões (IETS). In: Anais da 25a Reunião Anual da Sociedade Brasileira de Tecnologia de Embriões, Cumbuco, CE, Brasil. Acta Scientiae Veterinariae.

Wildman, E. E.; Jones, G. M.; Wagner, P. E.; Boman, R. L.; Troutt, H. F. and Lesch, T. N. 1982. A dairy cow body condition scoring system and its relationship to selected production characteristics. Journal of Dairy Science 65:495-501. 